\title{
STRUKTUR DRAMATIK PERTUNJUKAN DRAMA KLASIK SANGGAR TEATER MINI LAKON DEWA RUCI KAJIAN BENTUK DAN FUNGSI
}

\author{
Oleh \\ I Made Rudita \\ Dosen STIMIK STIKOM Bali \\ ruditalengar@yahoo.co.id
}

\begin{abstract}
ABSTRAK
Pada dasarnya nilai pendidikan karakter mempunyai tiga bagian yang saling bekaitan, yaitu pengetahuan moral, penghayatan moral dan perilaku moral. Oleh karena itu seseorang dengan karakter yang baik, mengetahui, menginginkan, dan melakukan yang baik. Ketiganya merupakan syarat untuk menuntun hidup yang bermoral dan membangun kematangan moral. Dalam melakukan pendidikan karakter tidak harus dengan menambah program tersendiri, melainkan bisa melalui transformasi budaya, salah satunya nilai-nilai pendidikan karakter bisa disampaikan melalui seni pertunjukan drama, khususnya pertunjukan drama klasik. Untuk menjawab masalah di atas, dalam hal mengetahui nilai pendidikan karakter melalui transformasi budaya Bali berupa pertunjukan drama klasik Sanggar Teater Mini, perlu dibuat suatu penelitian mengenai nilai pendidikan karakter dalam pertunjukan drama klasik Sanggar Teater Mini dengan lakon Dewa Ruci. Penelitian ini berjudul "Struktur Dramatik Pada Pertunjukan Drama Klasik Sanggar Teater Mini lakon Dewa Ruci".Kajian (Bentuk dan Fungsi)" adalah hasil studi yang mendalam struktur dramatik pada pertunjukan drama klasik. Penelitian ini mengangkat dua pokok masalah yaitu : 1) untuk mengetahui dan menganalisis bentuk struktur dramatik pertunjukan drama klasik Sanggar Teater Mini lakon Dewa Ruci ; 2) untuk mengetahui dan menganalisis fungsi pertunjukan drama klasik Sanggar Teater Mini lakon Dewa Ruci. Secara umum, penelitian ini bertujuan untuk mengetahui keberadaan dan peranan penting dari nilai-nilai pendidikan karakter dalam pertunjukan pertunjukan drama klasik Sanggar Teater Mini lakon Dewa Ruci . Secara khusus, penelitian ini bertujuan untuk menjelaskan bentuk struktur dramatik dan fungsi pertunjukan drama klasik Sanggar Teater Mini lakon Dewa Ruci. Penelitian ini dirancang sebagai penelitian kualitatif dengan menggunakan dua teori : teori estetika dan teori fungsional struktural. Metode-metode pengumpulan data yang digunakan meliputi observasi, wawancara, dokumentasi dan kepustakaan.Seluruh data diolah menggunakan tehnik deskriptif interpretatif. Hasil dari penelitian ini adalah sebagai berikut ; Bentuk struktur dramatik pertunjukan drama klasik Sanggar Teater Mini lakon Dewa Ruci adalah sebagai berikut : (1) tema, (2) alur, (3) latar, (4) penokohan, (5) insiden dan (6) amanat. Sedangkan fungsi drama klasik Sanggar Teater Mini lakon Dewa Ruci adalah sebagai berikut : (1) fungsi ekonomi, (2) fungsi hiburan, (3) fungsi promosi dan (4) fungsi komunikasi.
\end{abstract}




\begin{abstract}
Basically, the value of character education has three interrelated parts, namely moral knowledge, moral appreciation and moral behavior. Therefore someone with good character, knows, wants, and does good. All three are conditions for guiding a moral life and building moral maturity. In doing character education does not have to add a separate program, but it can be through cultural transformation, one of which is the values of character education can be conveyed through drama performing arts, especially classical drama performances. To answer the above problem, in terms of knowing the value of character education through the transformation of Balinese culture in the form of a classic Mini Theater studio performance, it is necessary to make a study of the value of character education in the performance of the Sanggar Teater Mini classic drama with Dewa Ruci play. This research entitled "Dramatic Structure of the Classical Drama Performance of Teater Mini lakon Dewa Ruci". Studies (Forms and Functions) "are the results of an in-depth study of the dramatic structure of classical drama performances. This research raises two main issues, namely: 1) to find out and analyze the dramatic structural forms of the Sanggar Teater Mini classical drama performance Dewa Ruci play; 2) to find out and analyze the function of the Sanggar Teater Mini lakon Dewa Ruci performance. In general, this study aims to find out the existence and important role of character education values in the performance of the classic Sanggar Teater Mini lakon Dewa Ruci performance. Specifically, this study aims to explain the dramatic structure and function of the classical drama performances of Sanggar Teater Mini Dewa Ruci play. This research was designed as qualitative research using two theories: aesthetic theory and structural functional theory. Data collection methods used include observation, interviews, documentation and literature. All data are processed using interpretive descriptive techniques. The results of this study are as follows; The form of the dramatic structure of the Sanggar Teater Mini classical drama performances by Dewa Ruci are as follows: (1) theme, (2) plot, (3) background, (4) characterization, (5) incident and (6) mandate. While the function of the classical drama Sanggar Teater Mini lakon Dewa Ruci is as follows: (1) economic function, (2) entertainment function, (3) promotion function and (4) communication function.
\end{abstract}

\section{PENDAHULUAN}

Berkesenian bagi masyarakat

Bali, merupakan kegiatan yang paling menonjol dalam kehiduapan seharihari. Tumbuh suburnya kegiatan berkesenian Bali ini disebabkan oleh dorongan yang kuat masyarakat Bali yang sebagian besar menganut agama Hindu. Agama Hindu memiliki unsurunsur rasional, ritual dan kepercayaan. Kegiatan berkesenian Bali ini di dalam pelaksanaannya sering dijadikan sebagai drama ritual dan sebagai persembahan kepada Tuhan. Kegiatan 
ini diharapkan dapat menjadi sarana bersumberkan pada Itihasa, yakni cerita untuk memperkuat rasa bhakti kepada Mahabarata dan Ramayana. Drama Tuhan.

Keberhasilan dalam menggarap klasik yang dimaksud Anom Ranuara tidak sebatas memainkan cerita drama "Jayaprana" disusul dengan pewayangan, namun juga permintaan untuk mengolah cerita- dikembangkan dengan menampilkan cerita tradisional lainnya. Untuk itu, cerita-cerita rakyat yang mengisahkan Anom Ranuara mencoba mengangkat peristiwa sekitar abad ke-10 sampai kedunia pewayangan yang bersumber dari 14 masehi, yang digolongkannya ke Mahabarata dan Ramayana. Setelah dua dalam kisah-kisah klasik (Jiwa Atmaja, kali penayangan di televisi, Anom 2009:152-153).

Ranuara kemudian ditanyai oleh bagian Pertunjukan drama klasik penyiaran TVRI mengenai apa nama Sanggar Teater Mini dalam fungsinya drama yang ditayangkan tersebut. dikatagorikan sebagai pertunjukan Apakah drama tradisional, drama balih-balihan (media hiburan). Dewasa modern, atau drama wayang. Anom ini pertunjukan drama klasik Sanggar Ranuara tersenyum, karena semua Teater Mini sangat digemari oleh nama tersebut mengena. Disebut drama masyarakat penontonnya, hal ini tradisional juga boleh, karena terbukti dari setiap pementasannya pemerannya semua menggunakan selalu dipenuhi oleh para kostum tradisional, disebut drama penggemarnya. Oleh karena itu modern karena dialog para pemainnya menurut pengamatan penulis, ketika diatur dalam naskah dan tidak menyaksikan pertunjukan drama klasik berimprovisasi sendiri-sendiri. Disebut Sanggar Teater Mini dengan lakon drama pewayangan juga boleh, karena Dewa Ruci mempunyai struktur kisah yang diangkat adalah cerita dramatik dan fungsi yang menarik, hal pewayangan. Dari semua itu, kemudian inilah yang melatar belakangi sehingga Anom Ranuara mengambil jalan penulis menjadikannya sebagai objek tengah, yakni dengan menyebut 'drama penelitian.

klasik' karena ia mementaskan atau II. PEMBAHASAN menampilkan cerita-cerita klasik yang 
3.1 Bentuk Struktur Dramatik tersebut dengan rasa penuh tanggung Pertunjukan Drama Klasik jawab.

Sanggar Teater Mini dengan b. Alur

lakon Dewa Ruci

Dalam Kamus Bahasa struktur memiliki beberapa pengertian, antara lain : (1) cara sesuatu disusun atau dibangun; (2) bangunan yang disusun dengan pola tertentu; (3) pengaturan unsur atau bagian suatu benda; (4) ketentuan unsur-unsur dari suatu benda. Struktur adalah rangkaian penyusunan dari karya sastra. Jika dilihat dari strukturnya maka cerita Dewa Ruci terdiri dari : tema, alur, penokohan, memasuki hutan Palasara, sebuah hutan insiden, dan amanat. Dan selanjutnya yang sangat angker madurgama. Lalu akan dipaparkan secara rinci dalam Bhima bertemu dengan dua orang uraian berikut.

\section{a.Tema}

Tema dari cerita Dewa Ruci adalah tentang kesetiaan seorang murid terhadap perintah seorang guru, dimana guru Drona memberi tugas kepada Bhima untuk mencari tirta Amerta, Lalu Bhima bertemu dengan Dewa sebagai tugas akhir dari pendidikannya. Indra dan Dewa Bayu yang merupak Walaupun sesungguhnya bagi Bhima benda yang bernama Tirta Amerta itu terasa abstrak dan tidak jelas dimana keberadaannya, namun sebagai bentuk kesetiaannya akan perintah seorang guru, maka Bhima menerima tugas
Alur cerita yang terdapat dalam cerita Dewa Ruci ini adalah alur maju, karena dalam cerita Dewa Ruci ceritanya bergerak maju dan menceritakan peristiwa dalam cerita tersebut dari awal hingga akhir. Awal ceritanya dimulai saat guru Drona memberi tugas kepada Bhima untuk mencari tirta Amerta, sebagai tugas akhir dari pendidikannya, lalu Bhima melanjutkan perjalanannya dan raksasa penghuni hutan tersebut yang bernama Rukmuka dan Rukmakala. Kemudia terjadi perkelahian yang sengit antara Bhima dengan kedua raksasa penjaga hutan tersebut dan akhirnya kedua raksasa itu terbunuh. reinkarnasi dari kedua raksasa penjaga hutan tersebut. Konon Dewa Indra dan Dewa Bayu melakukan sebuah kesalahan di sorga, sehingga Hyang Mahadewa menghukum mereka berdua dengan cara mengurung mereka di 
dalam tubuh dua raksasa penjaga hutan ini. Setelah mendapat petunjuk dari Dewa Bayu, agar Bhima menuju arah selatan. Setelah berjalan ke arah selatan lalu Bhima tiba didepan mulut sebuah goa dan dari dalam goa munculah seekor ular naga yang bergerak ke sanake mari, kemudian dia melintang di depan mulut goa. Tiba-tiba naga itu menggeliat dan menyerang, maka terjadilah pertarungan yang sengit antara Bhima dengan ular naga tersebut, sampai akhirnya ular naga itu mati. Lantas terjadi keanehan, dari tubuh ular naga tersebut muncullah seorang bidadari yang bernama Maheswari. Konon Dewi Maheswari ini pernah berbuat dosa di kahyangan sehingga Hyang Mahadewa menghukumnya dengan cara mengurungnya di dalam tubuh ular naga di bumi ini. Lalu atas petunjuk Dewi Maheswari bahwa Tirta Amerta itu berada di tengah samudra pantai selatan. Akhirnya Bhima bertemu Dewa Ruci dan mendapatkan Tirta Amerta tersebut. Cerita Dewa Ruci ini menggunakan alur maju, karena tidak ada penceritaan ke belakang.

\section{c. Latar}

Latar merupakan bagian cerita yang akan membangun suatu hal yang menarik dalam kaitannya dengan tempat, waktu dan suasana terjadinya suatu cerita. Melalui batasan tersebut diatas dapat dilihat adanya penekanan terhadap adanya unsur waktu, tempat dan keadaan sebagai unsur latar dalam cerita Dewa Ruci, adalah sebagai berikut :

\section{Pasraman Guru Drona adalah} sebuah tempat untuk menutut ilmu bagi putra-putra dari kerajaan Astinapura yakni Pendawa dan Korawa. Pada saat peristiwa ini terjadi Pendawa dan Korawa tengah menginjak usia remaja. Diusia seperti ini mereka diwajibkan mengikuti tahapan kehidupan Brahmacari Ashrama, yaitu mempelajari berbagai macam ilmu di bawah bimbingan guru besar Drona.

2. Hutan Palasara adalah sebuah hutan yang sangat angker maduragama. Hutan ini menyimpan sejumlah cerita tentang orang-orang yang pernah memasuki atau melewatinya namun tidak pernah kembali dalam keadaan selamat. 
Mungkinkah mereka mati karakter yang baik, tegas, jujur, dimangsa binatang buas, atau memiliki kekuatan yang luar biasa, terperosok ke dalam jurang hormat kepada guru dan orang-orang kegelapan, atau dilenyapkan oleh yang lebih tua serta masih banyak sifatmakhluk-makhluk halus ? Tidak sifat baik lainnya yang dimilikinya. seorangpun yang tahu. Bhima adalah seorang ksatria yang

3. Mulut Goa adalah sebuah tempat sangat berani, ia sangat memegang dimulut goa yang dijaga oleh teguh prinsip-prinsip perbuatan baik seekor ular naga yang sangat selama berada di jalan kebenaran besar.

(dharma), (2) tokoh Drona ia lahir

4. Tengah samudra pantai selatan dalam keluarga brahmana (kaum adalah sebuah samudra yang pendeta Hindu). Ia adalah putera dari sangat keramat. Masyarakat di pendeta Bharadwaja.

5. Sekitarnya menghormatinya Ketika mudanya, Drona bernama sebagai kawasan suci. Untuk Bambang Kumbayana. Ketika itu Resi memasukinya, tidak cukup hanya Drona begitu gagah dan tampan. dengan berbekal pikiran dan Pakaian yang dikenakan Bambang perkataan yang suci, tetapi harus Kumbayana selalu mewah dan diimbangi dengan perbuatan yang meyakinkan. Tetapi ketampanannya suci pula. Jangan merusak menjadi hilang setelah dia dihajar kawasan suci itu, walaupun habis-habisan oleh patih Gandamana. sedikit saja. Jika ada yang berani Resi Drona selalu berkostum jubah melanggar maka dewa samudra Pandhita. Drona dikenal dengan watak akan murka.

\section{d. Penokohan}

'bermuka dua' dan penuh prasangka

Adapun tokoh-tokoh yang sebagai pandhita, namun. Drona juga terlibat dalam cerita Dewa Ruci ini, dikenal sangat suka mendatangi para adalah sebagai berikut ; (1) tokoh muridnya, agar dihormati oleh muridBhima adalah tokoh utama dan murid dan keluarganya. Semua merupakan tokoh berkembang dalam kebutuhannya disediakan. Di balik cerita Dewa Ruci ini. Bhima memiliki jubahnya itu, Drona suka 
menyalahgunakan kebaikan setiap sebagai tugas akhir dari pendidikannya. orang yang minta pertolongan, untuk Pantang bagi Bhima untuk menolak kepentingan Drona sendiri. Drona tugas seorang guru yang dibebankan sering bercerita tentang kepadanya walaupun Bhima sendiri keberhasilannya dalam menolong tidak tahu wujud benda yang bernama sesama, sehingga para tamunya terbius Tirta Amerta itu dan tidak jelas pula oleh bujukannya, (3) Dewa Ruci adalah dimana keberadaan benda tersebut, (2) nama seorang Dewa kerdil (mini) yang insiden kedua terjadi saat Bhima dijumpai oleh Bhima atau Werkudara memasuki hutan Palasara. Hutan dalam sebuah perjalanan mencari air Palasara adalah sebuah hutan yang kehidupan (Tirta Amerta). Ruci berarti sangat angker maduragama. Hutan ini halus, maka Dewa Ruci berarti juga menyimpan sejumlah cerita tentang Dewa yang halus. Dewa Ruci dewanya orang-orang yang pernah memasuki Sang Werkudara atau Bhima, ialah atau melewatinya namun tidak pernah bentuk halusnya Sang Werkudara atau kembali dalam keadaan selamat. Bhima. Nama Dewa Ruci kemudian Mungkinkah mereka mati dimangsa diadopsi menjadi lakon atau judul binatang buas, atau terperosok ke dalam pertunjukan wayang, yang berisi ajaran jurang kegelapan, atau dilenyapkan atau falsafah hidup masyarakat Hindu- oleh makhluk-makhluk halus ? Tidak Bali.

\section{e. Insiden}

Insiden peristiwa atau kejadian yang terkandung dalam cerita, baik besar atau kecil yang secara keseluruhan menjadi kerangka yang membentuk struktur cerita. Berbekal dari pengertian inilah analisis insiden diuraikan sebagai berikut ; (1) insiden pertama terjadi saat guru Drona memberi tugas kepada Bhima untuk mencari Tirta Amerta, sumber udara bersih. Tanpa itu semua ini Bhima bertemu dua orang raksasa yang bernama Rukmuka dan Rukmakala. Bagi kedua raksasa itu hutan adalah kawasan suci yang harus dijaga kelestariannya. Semua hutan baik yang terletak dilereng gunung maupun di puncak gunung, sangat berguna bagi kelangsungan kehidupan. Di sana ada sumber air, ada makanan, ada sumber kekayaan, di sana ada seorangpun yang tahu. Didalam hutan sumber udara bersih. Tanpa itu semua 
tamatlah kehidupan di bumi ini. Karena Bhima bersikeras untuk memasuki kawasan hutan Palasari itu, dan kedua raksasa itu melarangnya, maka akhirnya kedua raksasa itu menyerang Bhima. Perkelahian sengitpun terjadi dan pada akhirnya kedua raksasa itu mati terbunuh di tangan Bhima, (3) insiden ketiga terjadi saat Bhima bertemu dengan seekor ular naga di depan mulut sebuah goa. Sebenarnya Bhima lebih suka menghindari pertemuan dengan siapa saja dalam hutan ini untuk mencegah terjadinya ketegangan. Tiba-tiba saja ular naga itu menggeliat dan mulai menyerang Bhima. Maka terjadilan pertarungan yang menegangkan, sampai akhirnya ular naga itu mati mengenaskan di tangan Bhima, (4) insiden keempat terjadi saat Bhima bertemu dengan Dewa Ruci. Dewa Ruci adalah nama seorang Dewa kerdil (mini) yang dijumpai oleh Bhima atau Werkudara dalam sebuah perjalanan mencari air kehidupan (Tirta Amerta). Ruci berarti halus, maka Dewa Ruci berarti juga Dewa yang halus. Dewa Ruci dewanya Sang Werkudara atau Bhima, ialah bentuk halusnya Sang Werkudara atau Bhima. Nama diadopsi menjadi lakon atau judul pertunjukan wayang, yang berisi ajaran atau falsafah hidup masyarakat HinduBali. Disinilah Dewa Ruci memberi wejangan kepada Bhima bahwa Tirta Amerta itu adalah air kehidupan yang tidak lain adalah nama lain dari Hyang Widhi itu sendiri. Itulah sebabnya Dewa Ruci mengatakan bahwa Tirta Amerta itu ada di mana-mana. Dia ada dalam diriku, Dia ada dalam dirimu, Dia ada dalam diri semua makluk hidup. Dia ada di sana, Dia ada di sini. Dia ada jauh, juga Dia ada dekat.

\section{f. Amanat}

Amanat yang terkandung di dalam cerita Dewa Ruci ini adalah tentang kesetiaan seorang murid terhadap perintah seorang guru sebagai bentuk penghormatan kepada jasa seorang guru yang telah memberikan ilmu pengetahuan kepada muridmuridnya. Bhima sangat patuh dan pasrah untuk melaksanakan perintah guru karena Bhima sangat yakin bahwa gurunya tidak akan mencelakai muridnya sendiri, sebagaimana seekor bayi kucing mempercayakan keselamatan jiwanya kepada induknya, ketika harus dipindahkan dari satu atap ke atap lainnya. 
memperoleh dana produksi dari Dinas

3.2 Fungsi Dramatik Pertunjukan Kebudayaan Provinsi Bali. Sedangkan

Drama Klasik Sanggar Teater pembagian keuntungan yang diperoleh

Mini dengan lakon Dewa Ruci dari hasil mencari sponsor ini,

\subsubsection{Fungsi Ekonomi}

Kesenian pada awalnya

merupakan seni yang sifatnya komunal, menjadi seni-seni yang dijajakan atau berfungsi ekonomi. Senada dengan pendapat diatas maka Soedarsono (1999:14) mengungkapkan bahwa produk-produk seni pertunjukan tradisional bisa dijual kepada penikmat dari masyarakat sendiri maupun kepada orang asing.

Tujuan diadakannya pertunjukan drama klasik Sanggar Teater Mini dengan lakon Dewa Ruci ini, salah satunya adalah untuk mencari keuntungan secara ekonomi. Hal ini sejalan dengan pendapat dari Adorno (1979:123) yang mengungkapkan bahwa sebuah produk dipasarkan adalah untuk mencari keuntungan. Adapun keuntungan yang diperoleh dalam pertunjukan drama klasik Sanggar Teater Mini dengan lakon Dewa Ruci ini adalah dari hasil mencari sponsor kepada instansi pemerintah maupun swasta yang bersifat tidak mengikat. Disamping memang disesuaikan dengan besar kecilnya peranan yang dimainkan dalam mendukung pementasan yang dilakukan.

Hal ini didukung oleh penuturan Ida Bagus Purwasila yang bertindak sebagai Ketua Sanggar dalam pertunjukan drama klasik Sanggar Teater Mini dengan lakon Dewa Ruci ini . Dalam wawawancara di rumahnya, Ida Bagus Purwasila mengatakan sebagai berikut :

"pertunjukan ini adalah sebuah bisnis, sama halnya seperti kita berjualan, bila partisipasi sponsor yang masuk banyak maka secara otomatis kita mendapat bagian keuntungan yang banyak tapi sebaliknya bila partisipasi sponsor sedikit maka kita juga sedikit mendapat bagian" (wawancara tanggal 31 Juli 2018 )

Dari ungkapan diatas bahwa pertunjukan drama klasik Sanggar Teater Mini dengan lakon Dewa Ruci ini memberikan manfaat ekonomi bagi pemain teater yang ada dan para pendukung pertunjukan, sehingga bisa dikatakan pertunjukan drama klasik Sanggar Teater Mini dengan lakon 
Dewa Ruci ini memiliki fungsi hadirnya para wisatawan nusantara ke ekonomi.

\subsubsection{Fungsi Hiburan}

Pertunjukan drama klasik arena Pesta Kesenian Bali, dimana pertunjukan drama klasik Sanggar Sanggar Teater Mini dengan lakon fungsinya sebagai hiburan, dimana Dewa Ruci dalam fungsinya sebagai dalam pertunjukannya drama klasik hiburan, secara umum tidak ada Sanggar Teater Mini ini lebih kaitannya dengan pelaksanaan upacara menekankan kepada nilai-nilai hiburan keagamaan. dengan tujuan pokoknya

Pertunjukan drama klasik menyenangkan penonton.

Sanggar Teater Mini dengan lakon

Dewa Ruci bertujuan untuk menghibur

\subsubsection{Fungsi Promosi}

masyarakat yang dalam kesehariannya

Promosi adalah merupakan bergelut dengan upacara keagamaan. sebagai sebuah syarat untuk Disamping itu pertunjukan drama menjadikan orang atau produk menjadi klasik Sanggar Teater Mini dengan dikenal oleh orang banyak atau lakon Dewa Ruci disamping sebagai masyarakat luas. Dalam hal melakukan hiburan yang tidak ada kaitannya suatu promosi dalam bentuk apapun dengan pelaksanaan upacara maka media massa akan selalu terlibat keagamaan mempunyai berbagai didalammnya.

tujuan, misalnya tujuan politik, Pertunjukan drama klasik penyebarluasan program pemerintah, Sanggar Teater Mini dengan lakon pengenalan produk dan lain-lain.

Dewa Ruci sebagai sebuah atraksi

Kini pertunjukan drama klasik budaya ternyata merupakan salah satu Sanggar Teater Mini dengan lakon media promosi dalam mendatangkan Dewa Ruci untuk hiburan telah wisatawan nusantara untuk datang mengalami perkembangan, yaitu tidak berkunjung ke Bali. hanya menjadi hiburan masyarakat Pertunjukan drama klasik lokal Bali saja, tapi sudah juga Sanggar Teater Mini dengan lakon menyentuh para wisatawan dari Dewa Ruci ini yang dipromosikan nusantara, hal ini terbukti dengan melalui beberapa iklan di media massa 
dan beberapa selebaran, ternyata dapat berfungsi sebagai media promosi, yaitu 1) mempromosikan drama klasik sebagai produk budaya Bali yang adiluhung 2) mempromosikan tempat dimana drama klasik ini dipentaskan (Art Center), 3) mempromosikan seniman-seniman teater sebagai pelaku pertunjukan drama klasik dan mempromosikan event Pesta Kesenian Bali sebagai salah satu destinasi wisata yang menarik.

\subsubsection{Fungsi Komunikasi}

Komunikasi adalah proses penyampaian informasi-informasi, pesan-pesan, gagasan-gagasan, pengertian-pengertian dengan lambang yang mengandung arti dan makna.

Dalam pertunjukan drama klasik Sanggar Teater Mini dengan lakon Dewa Ruci ini maka komunikasi yang dilakukan oleh para pemain teater akan dapat memberikan pandangan, saran kepada para penonton lewat pertunjukannya. Disamping itu komunikasi yang dilakukan juga dapat menjadikan pertunjukan drama klasik Sanggar Teater Mini dengan lakon Dewa Ruci ini lebih mempunyai makna bagi penonton.
Dalam pertunjukan drama klasik Sanggar Teater Mini dengan lakon Dewa Ruci ini maka para pemain teater akan menyampaikan pandanganpandangan tentang hidup, cerminan masa lalu, masa kini dan masa mendatang lewat ajaran-ajaran, normanorma hidup yang ada di Bali berdasarkan nilai-nilai yang berlandaskan ajaran Hindu.

Dalam pertunjukan drama tradisional pada umumnya yang kebanyakan penontonnya adalah masyarakat lokal maka biasanya para pemain drama melakukan komunikasi dengan mempergunakan bahasa lisan berupa bahasa daerah Bali. Sedangkan untuk pertunjukan drama klasik Sanggar Teater Mini dengan lakon Dewa Ruci ini, komunikasinya selain mempergunakan bahasa lisan berupa bahasa daerah juga dibantu dengan menggunakan bahasa lisan berupa bahasa Indonesia.

Komonikasi dalam bahasa lisan dilakukan melalui dialog-dialog antar tokoh-tokoh dalam pertunjukan drama klasik. Sedangkan komunikasi dalam bahasa tulisan dilakukan dengan memberikan sinopsis sebelum pertunjukan drama klasik ini dimulai. 
Melalui pertunjukan drama klasik Miles, Mattew B. 1992. Analisis Data Sanggar Teater Mini dengan lakon Dewa Ruci ini komunikasi budaya terjadi, sehingga pertunjukan drama klasik Sanggar Teater Mini dengan lakon Dewa Ruci sebagai produk budaya Bali dikenal secara luas oleh masyarakat Indonesia.

\section{DAFTAR PUSTAKA}

Arikunto. 1989. Prosedur Penelitian : Suatu Pendekatan Praktis. Jakarta : Bina Aksara.

Alwasilah, C. 2002. Pokoknya Kualitatif Dasar-dasar Merancang dan Melakukan Penelitian Kualitatif, Bandung : Pustaka Jaya.

Djelantik, A.A. M 2004. Estetika Sebuah Pengantar, Bandung : Masyarakat Seni Pertunjukan Indonesia (MSPI).

Dibia, I Wayan. 2010.’Pertunjukan Wayang Kulit Bali dari Wacak ke Kocak". Makalah disajikan dalam Seminar Internasional dengan tema Aestetic of Shadow Puppet Theater. Institut Hindu Dharma Negeri (IHDN).Denpasar 12 Juni. Jiwa Atmaja. 2009. Tri Dasa Warsa Teater Mini Badung. Denpasar: Udayana University Press. Kualitatif Buku Sumber tentang Metode-metode Bara, Jakarta : UI Press..

Nasir, Moh. 1988. Metode Penelitian. Jakarta : Ghalia Indonesia.

Redana, I Made 2005. Panduan Praktek Penulisan Karya Ilmiah dan Proposal. IHDN Denpasar.

Rota, Ketut 1990 Retorika sebagai Ragam Bahasa Panggung dalam Seni Pertujukan Wayang Kulit Bali, Laporan Penelitian, STSI Denpasar.

Satori, 2010. Metodologi Penelitian Kualitatif, Bandung : Alfabeta

Setya Yuwana, 2001. Metode Penelitian Kebudayaan, Surabaya : Unesa Unipress

Sugiyono, 2010. Metode Penelitian Kuantitatif Kualitatif dan $R \& D$. Bandung : Alfa beta

Suwija, I Nyoman. 2007. "Kritik Sosial Wayang Kulit Inovatif Bali : Kajian Wacana Naratif'.(Desertasi). Denpasar : Universitas Udayana .

Tamburaka, Rustam E. 2002. Pengatar Ilmu Sejarah Teori Filsafat Sejarah, Sejarah Filsafat \& Iptek. Jakarta : Rineka Cipta. 
Wicaksana, I Dewa Ketut. 2007. Maknanya dalam masyarakat Wayang Sapuh Leger. Fungsi dan Bali. Denpasar : Bali Post. 